\title{
Chickpea Growers' Knowledge about Chickpea Production Technology in Junagadh District of Gujarat State, India
}

\author{
K. D. Tankodara ${ }^{1^{*}}$, M. M. Lakhalani ${ }^{2}$ and G. R. Gohil ${ }^{3}$ \\ ${ }^{1}$ Department of Agricultural Extension \& Communication, A.A.U., Anand -388 110, India \\ ${ }^{2}$ National Food Security Mission Project, Porbandar-360 575, India \\ ${ }^{3}$ Directorate of Extension Education, J.A.U., Junagadh-362 001, India \\ *Corresponding author
}

\section{A B S T R A C T}

\section{Keywords}

Chickpea growers, Chickpea production technology, Level of knowledge, Knowledge test

Article Info

Accepted:

15 April 2020 Available Online: 10 May 2020
Chickpea is one of the most important pulse crops of Gujarat state. In Gujarat, Saurashtra region is one of the most remarkable regions for chickpea cultivation and production. Junagadh district of Saurashtra region is very good producer district. Due to consider the importance of knowledge as a major aspect behind the yield of chickpea production, the present research work was conducted to study the level of chickpea growers' knowledge about recommended chickpea production technology through ex-post facto research design. Four talukas; Maliya, Keshod, Mendarda and Junagadh of Junagadh district were purposively selected for the research. Total three villages were randomly selected from each selected taluka and 10 farmers were randomly selected from each village. Thus, total sample size was 120 farmers. Level of knowledge was measured through teacher made knowledge test. The structured and pre tested interview schedule was prepared for the collection of information about knowledge level of chickpea growers. The study revealed that majority of the chickpea growers $(68.3 \%)$ had medium level of knowledge, followed by $27.5 \%$ had high level, $2.5 \%$ had low level, $1.7 \%$ had very high level and none of the chickpea growers had very low level of knowledge about recommended production technology.

\section{Introduction}

The area under the cultivation of chickpea is increasing every year as it is one of the most important pulse crops of India due to its qualitative as well as quantitative importance. It is one of the most important legume crops of Gujarat state. In Gujarat, Saurashtra region is one of the most remarkable regions for chickpea cultivation and production. Among various districts of Saurashtra region, Junagadh is very good producer district. Generally, the yield of production of chickpea is mainly depends upon chickpea growers' level of knowledge as well as their adoption of recommended chickpea production 
technology. Though, knowledge is the main aspect behind the adoption of production technology. Hence, it was high time to measure the level of knowledge of the chickpea growers about recommended production technology.

The main objectives of this study includes to study the level of knowledge of the chickpea growers about recommended chickpea production technology

\section{Materials and Methods}

Ex-post facto research design was adopted for the study. The present investigation was conducted in Junagadh district of Gujarat state. Junagadh district is one of the leading chickpea growing districts of South Saurashtra Agro-climatic zone of Gujarat State.

Out of 9 talukas of Junagadh district, 4 talukas viz. Maliya, Keshod, Mendarda and Junagadh were selected purposively for the studydue to favorable area of production for chickpea crop and familiar area for researcher. Three villages were selected randomly from the each selected talukas. Thus, total 12 villages were selected for the study.

A random sampling procedure was followed for the selection of the respondents and accordingly ten chickpea growers from each village were selected as respondents. Thus, 120 chickpea growers were selected for the study.To measures the knowledge level of the chickpea growers about recommended chickpea production technology, a teacher made knowledge test based scale developed by Jha and Singh (1970) was used with slight modification. The procedure followed by Magarvadiya and Patel (2014) was carried out to get appropriate result.
For preparation of knowledge test, the list of chickpea production practices as recommended by Junagadh Agricultural University was collected from Pulse Research Station and Office of Director of Research. These collected practices were considered to measure the level of knowledge of the chickpea growers with respect to chickpea production technology.

Total 60 questions were formulated from the collected recommended practices and chickpea growers were asked to answer them in yes or no. The correct answers were tick marked and assigned one score. The total numbers of tick marked items were the knowledge score of the individual chickpea grower about the knowledge test.

Following formula was used for calculating the knowledge index of individual chickpea grower.

$\mathrm{Ki}(\%)=\frac{\mathrm{x} 1+\mathrm{x} 2+\cdots+\mathrm{xn}}{\mathrm{N}} \times 100$

Where,

$\mathrm{Ki}=$ Knowledge index (in percentage)

$\mathrm{X} 1+\mathrm{X} 2 \ldots+\mathrm{Xn}=$ Total number of correct answer

$\mathrm{N}=$ Total number of questions

The chickpea growers were grouped into five levels of knowledge according to arbitrary classification on the basis of their knowledge index viz., very low, low, medium, high and very high.

\section{Results and Discussion}

Level of knowledge of the chickpea growers about recommended chickpea production technology is presented in table 1. From the table 1 and figure 1, it is clear that majority of the chickpea growers $(68.3 \%)$ were from medium level knowledge group with respect 
to recommended chickpea production technology, followed by $27.5 \%, 2.5 \%$ and $1.7 \%$ were in high, low and very high level of knowledge group, respectively. Here, not a single chickpea grower came into very low level of knowledge category. The probable reason behind this result might be chickpea growers' social participation, their extension contact as well as their exposure of various mass media which favorably helped them in getting information about recommended chickpea production technology.

Table.1 Distribution of chickpea growers according to their level of knowledge about recommended chickpea production technology $(n=120)$

\begin{tabular}{|c|l|c|c|}
\hline Sr. No. & \multicolumn{1}{|c|}{ Category } & Frequency & Percentage \\
\hline 1. & Very low level of knowledge (0.0 to 20.0 score) & 00 & 00.0 \\
\hline 2. & Low level of knowledge $(20.1$ to 40.0 score) & 03 & 02.5 \\
\hline 3. & Medium level of knowledge $(40.1$ to 60.0 score) & 82 & 68.3 \\
\hline 4. & High level of knowledge $(60.1$ to 80.0 score) & 33 & 27.5 \\
\hline 5. & Very high level of knowledge $(80.1$ to 100.0 score $)$ & 02 & 01.7 \\
\hline & Total & $\mathbf{1 2 0}$ & $\mathbf{1 0 0 . 0}$ \\
\hline
\end{tabular}

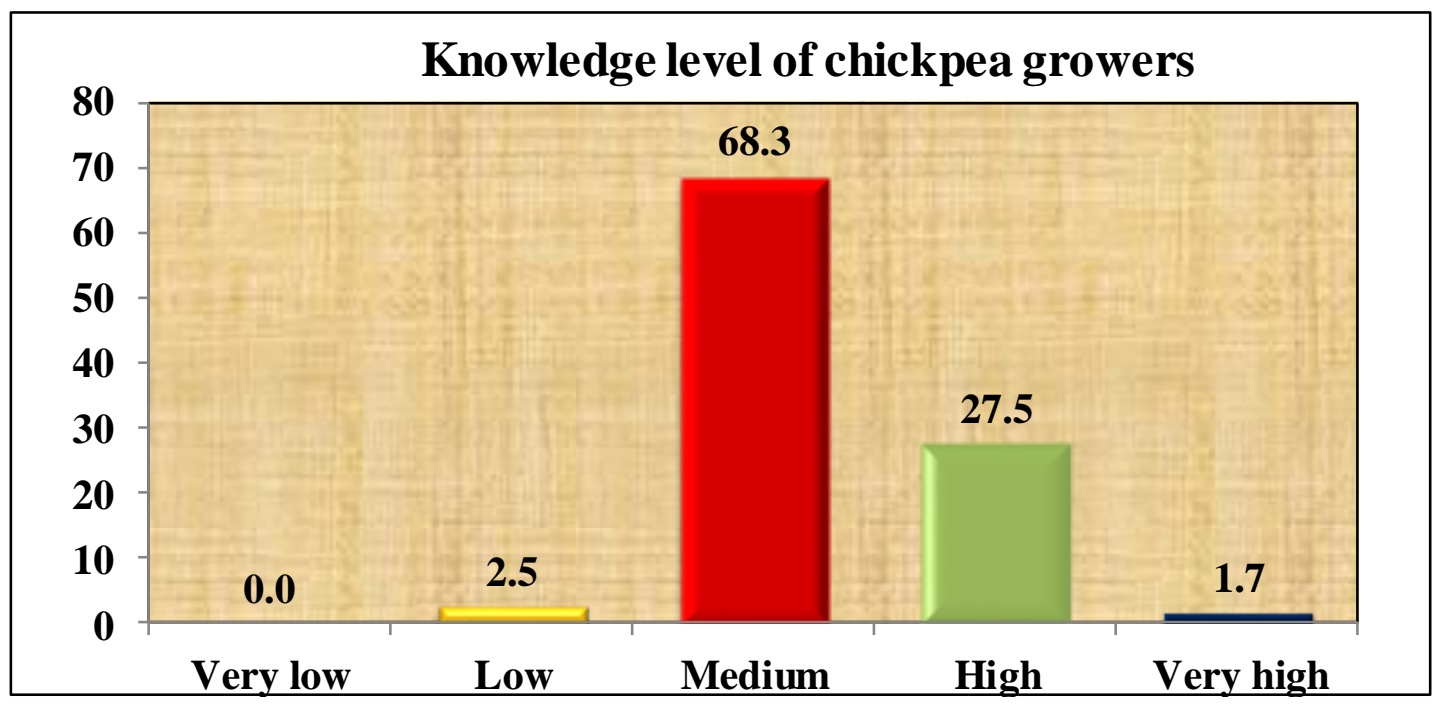

Figure.1 Distribution of chickpea growers according to their level of knowledge

This finding is in conformity with the findings of Umretiya (2015), Dhakad (2016) and Lohare (2017).

On the basis of entire study, it can be concluded that majority of the chickpea growers had medium to high level of knowledge about recommended chickpea production technology in Junagadh district of Gujarat state. This might be due to chickpea growers' active participation in various social and extension activities as well combine effort of Government and Agricultural University.

\section{Implication}

The study will serve as a guideline for the planners and extension agencies for planning and implementing various polices on chickpea 
crop as well as similar pulse crops' production in that area.

The study will work as review for the various researchers and enlightening the path in doing similar kind of work.

\section{References}

Dhakad, S. K. 2016. A study on training needs of chickpea growers in Morena block of Morena district. M.Sc. (Agri) Thesis (Unpublished), R.V.S.K.V.V., Gwalior.

Jha, P. N. and Singh, K. N. 1970. A test to measure farmers' knowledge about high yielding variety programme, Journal of
Interdiscipline, 7(1): 65-78.

Lohare, R. 2017. A study on knowledge and adoption of chickpea production technology among the farmers in Tirla block of Dhar district. M.Sc. (Agri) Thesis (Unpublished). R.V.S.K.V.V., Gwalior.

Magarvadiya, D. K. and Patel. V. T. 2014. Knowledge and attitude of farmers regarding biofertilizers. Gujarat Journal of Extension Education, 25(2): 149-151.

Umretiya, K. 2015. A comparative study on adoption of improved chickpea varieties in Indore district of Madhya Pradesh. M.Sc. (Agri) Thesis (Unpublished), R.V.S.K.V.V., Gwalior.

\section{How to cite this article:}

Tankodara, K. D., M. M. Lakhalani and Gohil, G. R. 2020. Chickpea Growers' Knowledge about Chickpea Production Technology in Junagadh District of Gujarat State, India. Int.J.Curr.Microbiol.App.Sci. 9(05): 1796-1799. doi: https://doi.org/10.20546/ijcmas.2020.905.203 